\title{
Influence of the polyol pathway on norepinephrine transporter reduction in diabetic cardiac sympathetic nerves: implications for heterogeneous accumulation of MIBG
}

\author{
Yasushi Kiyono, Satomi Kajiyama², Hiromi Fujiwara², Naoki Kanegawa², Hideo Saji² \\ ${ }^{1}$ Radioisotopes Research Laboratory, Hospital, Faculty of Medicine, Kyoto University, Kyoto 606-8507, Japan \\ ${ }^{2}$ Department of Patho-Functional Bioanalysis, Graduate School of Pharmaceutical Sciences, Kyoto University, Sakyo-ku, Kyoto 606-8501, \\ Japan \\ Published online: 9 July 2005 \\ (C) Springer-Verlag 2005
}

Eur J Nucl Med Mol Imaging (2005) 32:993-997

DOI $10.1007 / \mathrm{s} 00259-005-1865-1$

In the printed version of the article all of the tables are missing. The complete article, including the tables, is printed below.

\begin{abstract}
Purpose: Cardiac scintigraphic studies using ${ }^{123}$ I-labeled metaiodobenzylguanidine $\left(\left[{ }^{123} \mathrm{I}\right] \mathrm{MIBG}\right)$ have demonstrated heterogeneous myocardial accumulation of MIBG in diabetes. The accumulation has been found to correlate with a heterogeneous decrease in the expression of norepinephrine transporter (NET). In diabetic peripheral nerve tissue, polyol pathways are activated and cause nerve dysfunction and degeneration. However, there has been little research on the polyol pathway and cardiac sympathetic nerves. Therefore, to assess the influence of the polyol pathway on cardiac sympathetic nervous function, we investigated the regional accumulation of MIBG and NET protein expression in diabetic model rats treated with aldose reductase inhibitor (ARI) for the blockade of polyol pathways.

Methods: Rats were given a single intravenous injection of streptozotocin ( $n=76$, STZ-D rats). Starting the day after STZ injection, ARI was administered daily to 42 of the rats for 4 weeks (ARI-D rats). To assess the cardiac sympathetic nervous function, $\left[{ }^{125} \mathrm{I}\right] \mathrm{MIBG}$ autoradiographic experiments were carried out. Finally, NET protein expression was assessed with a saturation binding assay.
\end{abstract}

The online version of the original article can be found at http://dx.doi.org/10.1007/s00259-004-1694-7

\footnotetext{
Hideo Saji $(-)$

Department of Patho-Functional Bioanalysis,

Graduate School of Pharmaceutical Sciences,

Kyoto University,

Sakyo-ku, Kyoto, 606-8501, Japan

e-mail: hsaji@pharm.kyoto-u.ac.jp

Tel.: +81-75-7534556, Fax: +81-75-7534568
}

Results: The myocardial sorbitol concentration was significantly higher in STZ-D rats than in ARI-D rats. There was no heterogeneous accumulation of MIBG in ARI-D rats. There was a heterogeneous decrease of NET expression in STZ-D rats, but not in ARI-D or control rats.

Conclusion: The gathered data indicate that the enhanced polyol pathway correlates with the decrease in regional cardiac sympathetic nervous function, and this impairment may lead to the reduction of NET protein in cardiac sympathetic nerves of the diabetic inferior wall.

Keywords: MIBG - Norepinephrine transporter Sympathetic nervous system - Diabetes mellitus Polyol pathway

\section{Introduction}

The use of ${ }^{123}$ I-labeled metaiodobenzylguanidine $\left(\left[{ }^{123} \mathrm{I}\right]\right.$ MIBG), a radiolabeled analogue of norepinephrine (NE), has been introduced for visualization of denervation of the heart [1-3]. Cardiac scintigraphic studies using [ $\left.{ }^{123} \mathrm{I}\right] \mathrm{MIBG}$ have demonstrated heterogeneous abnormalities in cardiac MIBG accumulation in diabetes, starting in the inferior segments, with the progression of neuropathy [4-7]. In diabetic peripheral nerves, the activity of the polyol pathway increases. In this pathway, glucose is reduced to sorbitol by aldose reductase (AR) and subsequently sorbitol is metabolized to fructose via sorbitol dehydrogenase. The accumulation of sorbitol and/or fructose has been reported to lead to nervous degeneration and/or dysfunction in diabetic peripheral sites [8-10]. However, there has been little research on the polyol pathway and cardiac sympathetic nerves in the myocardium. Using type I and type II diabetic model rats, we have recently shown that the decrease in MIBG accumulation in the inferior segments correlates with a decrease in the level of norepinephrine transporter (NET), a carrier protein transporting MIBG into sympa- 
thetic nerve terminals, and is not dependent on regional myocardial blood flow or NE concentration [11, 12].

Against this background, we aimed to investigate whether the polyol pathway influences cardiac sympathetic nervous function. In previous studies on the influence of the polyol pathway, the pathway has been blocked by an aldose reductase inhibitor (ARI), an inhibitor of the ratelimiting enzyme of the polyol pathway $[8,13]$. For the purpose of this study, we investigated regional (anterior and inferior wall) concentrations of sorbitol, which is synthesized from glucose by AR, regional accumulation of MIBG, and regional NET expression in cardiac sympathetic nerves in ARI-administered streptozotocin (STZ)induced diabetic model (ARI-D) rats.

\section{Materials and methods}

\section{Chemicals}

$\left[{ }^{125} \mathrm{I}\right] \mathrm{MIBG}(17.28 \mathrm{TBq} / \mathrm{mmol})$ was supplied by Daiichi Radioisotope Laboratories (Tokyo, Japan). $\left[{ }^{3} \mathrm{H}\right]$ desipramine $(2.96 \mathrm{TBq} / \mathrm{mmol})$ was purchased from PerkinElmer Life Science (Boston, USA). Epalrestat, an aldose reductase inhibitor, was supplied by Ono Pharmaceutical Co., Ltd. (Osaka, Japan). All other chemicals used were of reagent grade.

\section{Animals}

Animal experiments were conducted in accordance with our institutional guidelines, and the experimental procedures were approved by the Kyoto University Animal Care Committee.

Seventy-six male Sprague-Dawley rats (6 weeks old, weighing 160-200 g; Japan SLC, Hamamatsu, Japan) were given a single intravenous injection of STZ (55 mg/kg body weight) via the tail vein. STZ was dissolved in $0.05 M$ citrate buffer at a concentration of $100 \mathrm{mg} / \mathrm{ml}$. Age-matched control rats $(n=36)$ were administered the citrate buffer solution only. Starting on the day after STZ injection, epalrestat $(100 \mathrm{mg} / \mathrm{kg}$ body weight) was administered daily through a gastric tube to 42 of the 76 STZ-injected rats for 4 weeks (ARI-D rats). Epalrestat was suspended in a solution of $0.5 \%$ carboxymethylcellulose at a concentration of $10 \mathrm{mg} / \mathrm{ml}$. All rats were housed for 4 weeks and given food and water ad libitum. Blood samples were collected on the day of the experiment, and serum glucose levels were measured by the glucose oxidase method (Glucose B-Test Wako, Wako Pure Chemical Industries, Osaka, Japan).

\section{Measurement of sorbitol concentration}

Sorbitol was measured as described previously with modifications [14]. Rats were sacrificed by decapitation under light ether anesthesia. Their hearts were excised and the ventricles were divided into four parts: anterior, lateral, inferior, and septal walls. The anterior and inferior walls were homogenized in 10 volumes of $8 \% \mathrm{HClO}_{4}$ with a 30 -s burst in a Polytron PT10-35 set at speed 6. Homogenates were centrifuged at $1,500 \times \mathrm{g}$ for $10 \mathrm{~min}$. Pellets were discarded and the supernatant was neutralized with $2 \mathrm{~N} \mathrm{~K}_{2} \mathrm{CO}_{3}$. Then, the neutralized mixtures were centrifuged at $1,500 \times g$ for $10 \mathrm{~min}$ and supernatants were filtered. Protein-free filtrate, $125 \mu \mathrm{l}$, was added to a reaction mixture, which consisted of $100 \mu$ of $0.25 \mathrm{mM}$ glycine buffer ( $\mathrm{pH}$ 9.5), $25 \mu$ of $12 \mathrm{mM}$ nicotinamide adenine dinucleotide (NAD), and $5 \mu \mathrm{l}$ of $22 \mathrm{U} / \mathrm{ml}$ of sorbitol dehydrogenase (SDH). Blanks, with either filtrate, NAD, or SDH deleted, were routinely run simultaneously. The mixtures were incubated for $40 \mathrm{~min}$ at $30^{\circ} \mathrm{C}$. Then the relative fluorescence due to NADH was measured by a FLEXstation (Molecular Devices, CA, USA) with an excitation wavelength of $350 \mathrm{~nm}$ and an emission wavelength of $440 \mathrm{~nm}$.

\section{Ex vivo autoradiographic studies in rats}

STZ-D rats $(n=5)$, ARI-D rats $(n=5)$, and control rats $(n=5)$, all 10 weeks old, were intravenously injected with $3.7 \mathrm{MBq}$ of $\left[{ }^{125} \mathrm{I}\right] \mathrm{MIBG}$. Then, $180 \mathrm{~min}$ after the injection, the rats were sacrificed by decapitation under light ether anesthesia, and their hearts were quickly excised, frozen, and cut into sections $20 \mu \mathrm{m}$ thick using a cryostat. The sections were thaw-mounted on precleaned silane-coated slides. The slides were placed on a Fuji Imaging Plate (BAS-UR, Fuji Photo Film, Japan) for $24 \mathrm{~h}$ along with calibrated ${ }^{125}$ I-labeled external standards ([ $\left[{ }^{125} \mathrm{I}\right]$ Microscales, Amersham, UK) to obtain $\left[{ }^{125} \mathrm{I}\right] \mathrm{MIBG}$ autoradiograms. Densitometric analyses of the autoradiograms were performed using a Bio Imaging Analyzer (BAS3000, FUJIFILM, Tokyo, Japan). The results regarding the uptake of radioactivity into various myocardial regions were expressed as the distribution absorption ratio (DAR), an index of radioligand accumulation corrected by body weight [15]. DAR values were derived from the following equation: DAR $=($ radioactivity of tissue $/ g$ of tissue $) \times($ body weight $/$ total injected dose)

\section{$\left[{ }^{3} H\right]$ Desipramine binding studies}

Membrane preparations for binding assays were prepared as described previously $[11,12]$. Rats were sacrificed by decapitation under light ether anesthesia. Their hearts were excised and the ventricles divided into four parts: the anterior, lateral, inferior, and septal walls. For each assay, 8-11 anterior and inferior walls were pooled and three experiments were performed. The anterior and inferior walls were homogenized in 20 volumes of ice-cold $250 \mathrm{mM}$ sucrose buffer ( $5 \mathrm{~m} M$ Tris, $1 \mathrm{mM} \mathrm{MgCl}$, and $250 \mathrm{~m} M$ sucrose) with a 30-s burst in a Polytron PT10-35 set at speed 6. Homogenates were centrifuged at $750 \times g$ for $10 \mathrm{~min}$. Pellets were discarded and the supernatant recentrifuged at $20,000 \times \mathrm{g}$ for $20 \mathrm{~min}$. The resulting pellets were resuspended in 10 volumes of ice-cold $50 \mathrm{mM}$ Tris- $\mathrm{HCl}$ buffer $(50 \mathrm{~m} M$ Tris, $5 \mathrm{mM} \mathrm{KCl}$, and $120 \mathrm{~m} M \mathrm{NaCl}$, pH 7.4) and recentrifuged to obtain a pellet. Pellets thus obtained were resuspended in 5 volumes of Tris- $\mathrm{HCl}$ buffer and stored at $-80^{\circ} \mathrm{C}$ prior to use. Protein concentrations were measured by the method of Lowry et al. [16].

Binding assays were performed as described previously with some modifications $[11,12]$. Briefly, $\left[{ }^{3} \mathrm{H}\right]$ desipramine binding was determined by incubating aliquots of membrane suspension with $\left[{ }^{3} \mathrm{H}\right]$ desipramine $(0.25-30 \mathrm{nM})$ in a final volume of $250 \mu \mathrm{l}$ for $30 \mathrm{~min}$ at $25^{\circ} \mathrm{C}$. The binding was terminated by diluting the incubation mixture with $5 \mathrm{ml}$ of ice-cold $50 \mathrm{mM}$ Tris- $\mathrm{HCl}$ buffer $(\mathrm{pH} 7.4)$ and filtering it through Whatman GF/B fiber filters using a 24-channel cell harvester (Brandel, Gaithersburg, MD, USA). Finally, the filters were rinsed three times, each time with $5 \mathrm{ml}$ of ice-cold $50 \mathrm{~m} M$ Tris$\mathrm{HCl}$ buffer ( $\mathrm{pH}$ 7.4). The radioactivity trapped by the filters was determined with a liquid scintillation counter (Tri-Carb 2500-TR Liquid Scintillation Analyzer, Packard). Nonspecific binding was defined using $100 \mu M$ nisoxetine. 
Table 1. General characteristics of experimental animals

\begin{tabular}{lccc}
\hline & $\begin{array}{l}\text { Control rats } \\
(n=36)\end{array}$ & $\begin{array}{l}\text { STZ-D rats } \\
(n=34)\end{array}$ & $\begin{array}{l}\text { ARI-D rats } \\
(n=42)\end{array}$ \\
\hline Body weight $(\mathrm{g})$ & $303 \pm 10$ & $185 \pm 33^{*}$ & $181 \pm 35^{*}$ \\
Heart weight $(\mathrm{g})$ & $0.94 \pm 0.08$ & $0.60 \pm 0.10^{*}$ & $0.56 \pm 0.09^{*}$ \\
$\begin{array}{l}\text { Plasma glucose } \\
(\mathrm{mg} / \mathrm{dl})^{\mathrm{a}}\end{array}$ & $142 \pm 22$ & $504 \pm 84^{*}$ & $492 \pm 73^{*}$ \\
\hline
\end{tabular}

Each value is the mean $\pm \mathrm{SD}$

${ }^{*} P<0.001$ vs corresponding value of control rats

aEach value is the mean \pm SD for 20 rats

Table 2. Regional sorbitol concentration (nmol/g tissue) in rat myocardium

\begin{tabular}{lcc}
\hline & Anterior wall & Inferior wall \\
\hline Control rats $(n=5)$ & $8.84 \pm 1.63$ & $6.31 \pm 1.17^{* * *}$ \\
STZ-D rats $(n=5)$ & $194 \pm 36^{*}$ & $218 \pm 37^{* * * * *}$ \\
ARI-D rats $(n=5)$ & $41.0 \pm 13.4^{* *}$ & $40.7 \pm 13.4^{* *}$ \\
\hline
\end{tabular}

Each value is the mean $\pm \mathrm{SD}$

${ }^{*} P<0.001$ vs corresponding value of control rats

${ }^{* *} P<0.001$ vs corresponding value of STZ-D rats

${ }^{* * *} P<0.05$ vs corresponding value of the anterior wall

\section{Statistical analyses}

Data are presented as mean values with SD. Comparisons within groups were performed using Student's $t$-test for paired data, and comparisons between groups were analyzed by one-way ANOVA, followed by the Tukey-Kramer multiple comparisons test. $P<0.05$ was considered statistically significant.

\section{Results}

\section{Characteristics of animals}

Table 1 summarizes the body weight, heart weight, and plasma glucose levels of the rats used in this study. These

Fig. 1. Representative autoradiograms for $\left[{ }^{125} \mathrm{I}\right] \mathrm{MIBG}$ in control, STZ-D, and ARI-D rats. physiological parameters were significantly different in STZ-D rats and ARI-D rats compared with control rats $(P<$ $0.001)$. There was no significant difference between STZ$\mathrm{D}$ and ARI-D rats.

\section{Sorbitol concentration}

To investigate the effects of epalrestat, we measured sorbitol concentrations in the anterior and inferior walls. As shown in Table 2, sorbitol concentrations in both walls in STZ-D rats were significantly higher than in control rats $(P<0.001)$. However, there was no significant difference in the sorbitol concentrations in either the anterior or the inferior wall between the ARI-D and control rats.

\section{Ex vivo autoradiographic studies}

To investigate the influence of the polyol pathway on cardiac sympathetic nervous function, we performed $\left[{ }^{125} \mathrm{I}\right]$ MIBG autoradiographic studies. Due to the large differences in body weight between the control and diabetic groups (STZ-D and ARI-D), we estimated the accumulation of radioligands as a DAR.

Figure 1 shows representative autoradiograms in control, STZ-D, and ARI-D rats. Table 3 shows the results in respect of regional myocardial accumulation of $\left[{ }^{125} \mathrm{I}\right]$ MIBG in the three groups. The uptake of $\left[{ }^{125} \mathrm{I}\right] \mathrm{MIBG}$ in control rats was similar between the anterior and the inferior wall. By contrast, in STZ-D rats, significantly less $\left.{ }^{125} \mathrm{I}\right] \mathrm{MIBG}$ was taken up in the inferior wall than in the anterior wall $(P<0.001)$. There was no significant difference between the anterior and inferior walls in ARI-D rats, and the ratio of inferior wall to anterior wall uptake in ARI$\mathrm{D}$ rats remained at the control level (control $1.00 \pm 0.07$, STZ-D $0.75 \pm 0.08$, ARI-D $1.11 \pm 0.10$ ).

\section{Binding experiments}

We determined the density of NET in myocardial membranes from the control, STZ-D, and ARI-D rats by ana-
STZ-D Rats

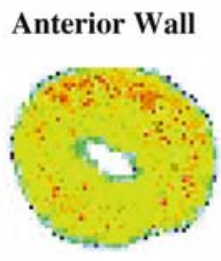

Inferior Wall
ARI-D Rats

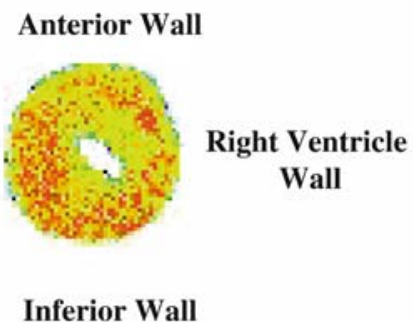

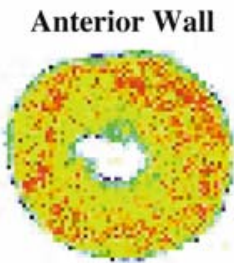

Inferior Wall

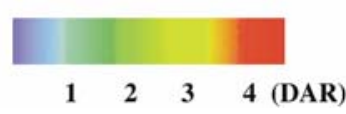


Table 3. Regional myocardial accumulation of [ $\left.{ }^{125} \mathrm{I}\right] \mathrm{MIBG}$ in rats

\begin{tabular}{lll}
\hline & Anterior wall & Inferior wall \\
\hline Control rats $(n=5)$ & $4.20 \pm 0.30$ & $4.18 \pm 0.39$ \\
STZ-D rats $(n=5)$ & $4.39 \pm 0.30$ & $3.27 \pm 0.38^{*}$ \\
ARI-D rats $(n=5)$ & $3.63 \pm 0.74$ & $4.04 \pm 0.85$ \\
\hline
\end{tabular}

Each value is the mean $\pm \mathrm{SD}$

${ }^{*} P<0.001$ vs the anterior wall value of STZ-D rats

Table 4. $B_{\max }$ values of regional rat heart

\begin{tabular}{lll}
\hline & $\begin{array}{l}\text { Anterior wall } \\
(\mathrm{fmol} / \mathrm{mg} \text { protein })\end{array}$ & $\begin{array}{l}\text { Inferior wall } \\
(\mathrm{fmol} / \mathrm{mg} \text { protein })\end{array}$ \\
\hline Control rats & $673 \pm 125$ & $682 \pm 130$ \\
STZ-D rats & $698 \pm 91$ & $590 \pm 64^{*}$ \\
ARI-D rats & $688 \pm 59$ & $697 \pm 30$ \\
\hline
\end{tabular}

The maximal specific binding, $B_{\max }$, was calculated by Scatchard analysis The results are the mean \pm SD of three experiments, each performed in triplicate

${ }^{*} P<0.05$ vs the anterior wall value of STZ-D rats

lyzing the binding of $\left[{ }^{3} \mathrm{H}\right]$ desipramine to the membranes. The specific binding of $\left[{ }^{3} \mathrm{H}\right]$ desipramine was saturable in the range of $0.25-30 \mathrm{n} M$ in the three groups. Scatchard analyses gave straight lines in all groups, indicating a single population of binding sites. The $B_{\max }$ was lower in the inferior wall than in the anterior wall in STZ-D rats $(P<$ $0.05)$. On the other hand, there was no significant difference between the anterior and inferior walls in the control or ARI-D rats (Table 4).

\section{Discussion}

It has been reported that the myocardial accumulation of $\left[{ }^{123} \mathrm{I}\right] \mathrm{MIBG}$ is lower than normal in diabetic patients, and that the decrease is greater in the inferior wall than in the anterior wall [5-7]. Recently, we demonstrated that the heterogeneous decrease in NET correlates with the heterogeneous accumulation of $\left.{ }^{123} \mathrm{I}\right] \mathrm{MIBG}[11,12]$.

On the other hand, it has been reported that in diabetic peripheral nerves, the accumulation of sorbitol, which is synthesized from glucose by AR, increases with a subsequent depletion of myo-inositol [17, 18]. This depletion leads to a reduction in the availability of diacylglycerol [19, 20], resulting in decreased neural PKC activity. Diminished PKC activity reduces the phosphorylation of $\mathrm{Na}^{+} / \mathrm{K}^{+}$ATPase, which in turn induces a deficit in nerve conduction and further nerve degeneration [10, 21, 22]. However, there has been little research on the polyol pathway and cardiac sympathetic nerves. Therefore, in this study, to elucidate the influence of the polyol pathway on cardiac sympathetic nervous function, we investigated regional (anterior and inferior walls) MIBG accumulation and NET expression in diabetic rats treated with epalrestat, an AR inhibitor (ARI-D rats).

The sorbitol concentrations of control rats were similar to those cited in a previous report [23]. In STZ-D rats, the sorbitol concentrations were more than 20 times higher than in the control values (Table 2). Furthermore, the sorbitol concentration of the inferior wall was significantly higher than that of the anterior wall $(P<0.05)$. On the other hand, in ARI-D rats, the sorbitol concentrations were suppressed to one-fifth of those of STZ-D rats (Table 2). These results indicate that epalrestat inhibits the activation of the polyol pathway in diabetic myocardium.

To study the influence of the polyol pathway on cardiac sympathetic nervous function, we carried out ex vivo autoradiographic experiments with $\left[{ }^{125} \mathrm{I}\right] \mathrm{MIBG}$. The uptake of $\left[{ }^{125} \mathrm{I}\right] \mathrm{MIBG}$ in control rats was similar in the anterior and inferior walls (Table 3). In contrast, significantly less $\left[{ }^{125} \mathrm{I}\right] \mathrm{MIBG}$ was taken up in the inferior wall than in the anterior wall in STZ-D rats (Table 3). Moreover, there was no significant difference between anterior and inferior wall uptake in ARI-D rats. These results show that the cardiac sympathetic nervous function was impaired by the polyol pathway in diabetes, and this impairment was prevented by the blockade of the polyol pathway.

To elucidate the cause of the reduced sympathetic nervous function in the inferior wall of STZ-D rats, the expression of NET, which is located presynaptically on the noradrenergic nerve terminal and plays a critical role in the regulation of the synaptic NE concentration [24], was assessed by determining the $B_{\max }$ values of both anterior and inferior walls in the three groups. In control rats, there was no significant difference in the $B_{\max }$ value between the anterior and inferior walls (Table 4). In contrast, the $B_{\max }$ value was significantly lower for the inferior wall than the anterior wall in STZ-D rats, while there was no significant difference in $B_{\max }$ value between the anterior and inferior walls in ARI-D rats (Table 4). These results indicate that the polyol pathway has an influence on regional NET protein expression in cardiac sympathetic nerves.

It has been reported that the activated polyol pathway leads to nerve degeneration and/or dysfunction via a reduction of PKC activity [19-22]. Moreover, Addicks et al. [25] demonstrated a decrease in the number of sympathetic nerve fibers and severe structural abnormalities of sympathetic nerves in myocardium of diabetic model rats. Therefore, the decreased NET expression may be due to the sympathetic nervous dysfunction or the loss of sympathetic nerve fibers. On the other hand, it has also been reported that in diabetes the activated polyol pathway leads to the activation of PKC [26-28] and that PKC regulates the surface expression of NET [29-31]. Thus, there is a possibility that this PKC activation decreased the NET expression. Further studies concerning PKC activity in cardiac sympathetic nerves are required.

The gathered data indicate that the enhanced polyol pathway correlates with the decrease in regional cardiac sympathetic nervous function, and that this impairment may lead to reduction of NET protein in the cardiac sympathetic nerves of the diabetic inferior wall. 
Acknowledgments. This study was supported in part by Grants-inAid for General Scientific Research from the Ministry of Education, Culture, Sports, Science, and Technology of Japan and the 21st Century COE Program "Knowledge Information Infrastructure for Genome Science". We would like to thank Daiichi Radioisotope Laboratories Ltd., Tokyo, Japan, for providing $\left[{ }^{125} \mathrm{I}\right] \mathrm{MIBG}$, and Ono Pharmaceutical Co., Ltd., Osaka, Japan for providing epalrestat.

\section{References}

1. Hattori N, Schwaiger M. Metaiodobenzylguanidine scintigraphy of the heart: what have we learnt clinically? Eur J Nucl Med 2000;27:1-6.

2. Lanza GA. Abnormal cardiac nerve function in syndrome $X$. Herz 1999;24:97-106.

3. Merlet P, Valette H, Dubois-Rande JL, Mardon K, Pouillart F, Bourachot ML, et al. Iodine 123-labeled metaiodobenzylguanidine imaging in heart disease. J Nucl Cardiol 1994;1:S79-85.

4. Hattori N, Tamaki N, Hayashi T, Masuda I, Kudoh T, Tateno $\mathrm{M}$, et al. Regional abnormality of iodine-123-MIBG in diabetic hearts. J Nucl Med 1996;37:1985-90.

5. Kreiner G, Wolzt M, Fasching P, Leitha T, Edlmayer A, Korn A, et al. Myocardial $m-\left[{ }^{123} \mathrm{I}\right]$ iodobenzylguanidine scintigraphy for the assessment of adrenergic cardiac innervation in patients with IDDM. Comparison with cardiovascular reflex tests and relationship to left ventricular function. Diabetes 1995;44:543-9.

6. Langer A, Freeman MR, Josse RG, Armstrong PW. Metaiodobenzylguanidine imaging in diabetes mellitus: assessment of cardiac sympathetic denervation and its relation to autonomic dysfunction and silent myocardial ischemia. J Am Coll Cardiol 1995;25:610-8.

7. Schnell O, Kirsch CM, Stemplinger J, Haslbeck M, Standl E. Scintigraphic evidence for cardiac sympathetic dysinnervation in long-term IDDM patients with and without ECG-based autonomic neuropathy. Diabetologia 1995;38:1345-52.

8. Yagihashi S, Yamagishi SI, Wada Ri R, Baba M, Hohman TC, Yabe-Nishimura $\mathrm{C}$, et al. Neuropathy in diabetic mice overexpressing human aldose reductase and effects of aldose reductase inhibitor. Brain 2001;124:2448-58.

9. Cameron NE, Cotter MA, Basso M, Hohman TC. Comparison of the effects of inhibitors of aldose reductase and sorbitol dehydrogenase on neurovascular function, nerve conduction and tissue polyol pathway metabolites in streptozotocin-diabetic rats. Diabetologia 1997;40:271-81.

10. Greene DA, Sima AA, Stevens MJ, Feldman EL, Killen PD, Henry DN, et al. Aldose reductase inhibitors: an approach to the treatment of diabetic nerve damage. Diabetes Metab Rev 1993;9:189-217.

11. Kiyono Y, Iida Y, Kawashima H, Tamaki N, Nishimura H, Saji $\mathrm{H}$. Regional alterations of myocardial norepinephrine transporter density in streptozotocin-induced diabetic rats: implications for heterogeneous cardiac accumulation of MIBG in diabetes. Eur J Nucl Med 2001;28:894-9.

12. Kiyono Y, Iida Y, Kawashima H, Ogawa M, Tamaki N, Nishimura $\mathrm{H}$, et al. Norepinephrine transporter density as a causative factor in alterations in MIBG myocardial uptake in NIDDM model rats. Eur J Nucl Med Mol Imaging 2002;29: 999-1005.

13. Greene DA, Arezzo JC, Brown MB. Effect of aldose reductase inhibition on nerve conduction and morphometry in diabetic neuropathy. Zenarestat Study Group. Neurology 1999;53:58091.
14. Malone JI, Knox G, Benford S, Tedesco TA. Red cell sorbitol: an indicator of diabetic control. Diabetes 1980;29:861-4.

15. Haaparanta M, Paul R, Huovinen R, Kujari H, Bergman J, Solin $\mathrm{O}$, et al. Pharmacokinetics and metabolism of $2-\left[{ }^{18} \mathrm{~F}\right]$ fluoro-2-deoxy-D-glucose (FDG) in mammary tumors of antiestrogen-treated rats. Nucl Med Biol 1995;22:483-9.

16. Lowry OH, Rosebrough NJ, Farr AL, Randall RJ. Protein measurements with the folin phenol reagent. J Biol Chem 1951; 193:265-75.

17. Finegold D, Lattimer SA, Nolle S, Bernstein M, Greene DA. Polyol pathway activity and myo-inositol metabolism. A suggested relationship in the pathogenesis of diabetic neuropathy. Diabetes 1983;32:988-92.

18. Mayhew JA, Gillon KR, Hawthorne JN. Free and lipid inositol, sorbitol and sugars in sciatic nerve obtained post-mortem from diabetic patients and control subjects. Diabetologia 1983;24: $13-15$.

19. Greene DA, Lattimer-Greene S, Sima AA. Pathogenesis of diabetic neuropathy: role of altered phosphoinositide metabolism. Crit Rev Neurobiol 1989;5:143-219.

20. Zhu X, Eichberg J. 1,2-Diacylglycerol content and its arachidonyl-containing molecular species are reduced in sciatic nerve from streptozotocin-induced diabetic rats. J Neurochem 1990; 55:1087-90.

21. Sima AA, Brismar T. Reversible diabetic nerve dysfunction: structural correlates to electrophysiological abnormalities. Ann Neurol 1985;18:21-29.

22. Stevens MJ, Feldman EL, Greene DA. The aetiology of diabetic neuropathy: the combined roles of metabolic and vascular defects. Diabet Med 1995;12:566-79.

23. Ramasamy R, Oates PJ, Schaefer S. Aldose reductase inhibition protects diabetic and nondiabetic rat hearts from ischemic injury. Diabetes 1997;46:292-300.

24. Amara SG, Kuhar MJ. Neurotransmitter transporters: recent progress. Annu Rev Neurosci 1993;16:73-93.

25. Addicks K, Boy C, Rosen P. Sympathetic autonomic neuropathy in the heart of the spontaneous diabetic BB rat. Ann Anat 1993; 175:253-7.

26. Greene DA, Sima AA, Stevens MJ, Feldman EL, Lattimer SA. Complications: neuropathy, pathogenetic considerations. Diabetes Care 1992;15:1902-25.

27. Vinik AI, Holland MT, Le Beau JM, Liuzzi FJ, Stansberry KB, Colen LB. Diabetic neuropathies. Diabetes Care 1992;15: 1926-75.

28. Cameron NE, Cotter MA. Effects of protein kinase $\mathrm{C} \beta$ inhibition on neurovascular dysfunction in diabetic rats: interaction with oxidative stress and essential fatty acid dysmetabolism. Diabetes Metab Res Rev 2002;18:315-23.

29. Apparsundaram S, Galli A, DeFelice LJ, Hartzell HC, Blakely RD. Acute regulation of norepinephrine transport. I. Protein kinase C-linked muscarinic receptors influence transport capacity and transporter density in SK-N-SH cells. J Pharmacol Exp Ther 1998;287:733-43.

30. Apparsundaram S, Schroeter S, Giovanetti E, Blakely RD. Acute regulation of norepinephrine transport. II. PKC-modulated surface expression of human norepinephrine transporter proteins. J Pharmacol Exp Ther 1998;287:744-51.

31. Amara SG, Sonders MS, Zahniser NR, Povlock SL, Daniels GM. Molecular physiology and regulation of catecholamine transporters. Adv Pharmacol 1998;42:164-8. 